\title{
INTRANET DEVELOPMENT AND DESIGN THAT WORKS
}

\author{
Bobby Baca and Andrea Cassidy \\ Department of Statistics and Human Factors \\ Sandia National Laboratories, Albuquerque, New Mexico \\ bgbaca@sandia.gov \& alcassi@sandia.gov
}

Making information available and easy to find is the objective of designing a good web site. A company's Intranet typically provides a great deal of information to its employees in an effort to help them better perform their jobs. If the information is available but is difficult to locate, the usefulness of this information is diminished.

Sandia National Laboratories performed a redesign of its home page and has obtained a successful design which enables its employees to locate information quickly and efficiently. Three phases of usability testing were conducted to develop and optimize the home page. This paper will discuss the redesign of the Intranet home page and describe how usability studies were used to help ensure a usable design.

\section{INTRODUCTION}

A company's Intranet has become a popular means for publishing information to employees. This allows them to obtain information quicker and more efficiently. Designers of Intranets have to understand the needs of the employees and analyze the scope of the content to be put on the site. Having a clear understanding of who the users are, what tasks they need to perform and what hardware and software environment they use will help focus the development effort. If employees are unable to locate information quickly because of disorganized pages and confusing information, they will not use this tool.

Sandia National Laboratories redesigned its Intranet home page based on usability engineering principles in an effort to allow its employees to locate desired information quickly with minimal effort. The Sandia National Laboratories Intranet is a very large and robust system of information and application links that range from administrative tasks to specific scientific data. Presenting this information on a home page in a way that is useful to all users is a monumental task. The goal of redesigning the home page was to make information easy to locate and to eliminate the guessing game of "what's under this link."

One of the major complaints with the old home page was that users were not able to locate the information they were searching for and did not have a good idea which link it might be under.

In redesigning the home page, designers attempted to develop a home page in which both technical and administrative users would be able to locate information $80 \%$ of the time with no more than two false paths (two incorrect top-level categories). This required rethinking the way information was divided into categories, as well as how it was presented on the home page and second level pages. From this premise our "adventure" began.

\section{THE OLD DESIGN}

The old home page had been in place for five years with only minor changes. It had 10 major graphical links that took users to ten 2 nd level pages. Once on a 2 nd level page they could navigate to the desired link by scrolling or by submenus. An additional 18 links on the home page launched specific applications. 


\section{DISCLAIMER}

This report was prepared as an account of work sponsored by an agency of the United States Government. Neither the United States Government nor any agency thereof, nor any of their employees, make any warranty, express or implied, or assumes any legal liability or responsibility for the accuracy, completeness, or usefulness of any information, apparatus, product, or process disclosed, or represents that its use would not infringe privately owned rights. Reference herein to any specific commercial product, process, or service by trade name, trademark, manufacturer, or otherwise does not necessarily constitute or imply its endorsement, recommendation, or favoring by the United States Government or any agency thereof. The views and opinions of authors expressed herein do not necessarily state or reflect those of the United States Government or any agency thereof. 


\section{DISCLAIMER}

Portions of this document may be illegible in electronic image products. Images are produced from the best available original document. 
Figure 1 - The Old Home Page Design

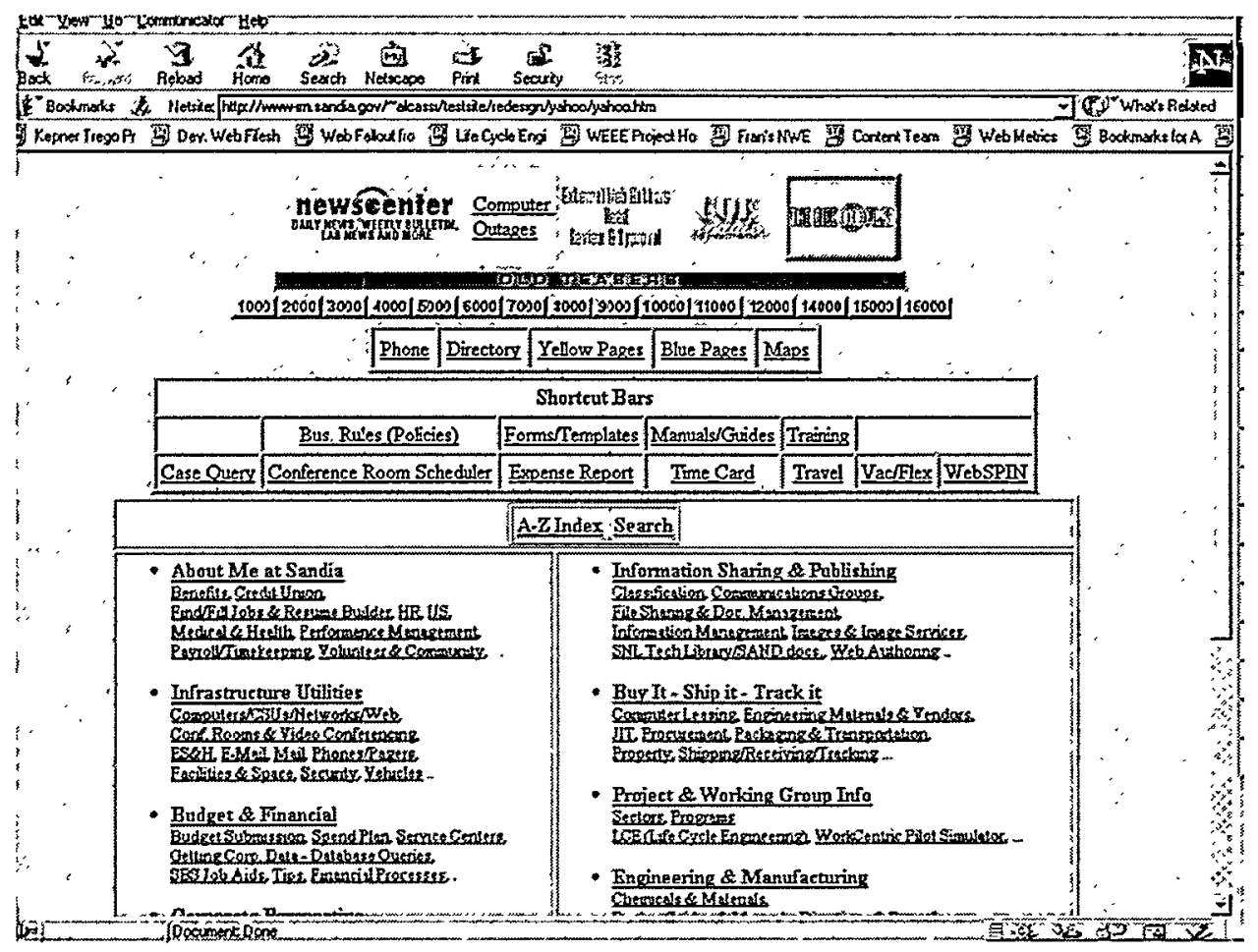

The major problem with this design was that users did not know what information they might find under the major graphical links.

\section{PHASE 1}

The initial redesign redefined the way information was chunked into major categories. We discarded the old categories and defined new categories of related information. We hoped this would solve the problem of users not understanding what information could be found under categories.

To give additional clues as to what information they would find under a category, we listed text "examples" immediately below each major category. Clicking an example took the user directly to that subcategory on the 2 nd level page. On the old design, subcategories had not been visible until the user got to a second level page.

Because there was not room on the homepage to list every subcategory, we choose a subset based on their predictive value (letting users know what to expect on the second level page). The names of the examples were chosen to be descriptive, easily understandable, and easily distinguished from other labels on the home page.

The initial prototype had eight major categories depicted in text. In addition, sixteen graphic "shortcut" buttons were emulated using rectangular colored backgrounds behind text.

The purpose of Phase 1 usability testing was to validate the new categories and the basic design, and to identify areas for improvement. Therefore, we defined tasks which required users to search for information on both the home and 2 nd level pages. The tasks required the user to find a specific . page/information on Sandia's Intranet.

Because Sandia employees held either a technical or administrative position, we defined both technical and administrative tasks. There were 20 technical and 12 administrative tasks, for a total of 32 tasks: 
Figure 2 - Phase 1 Prototype

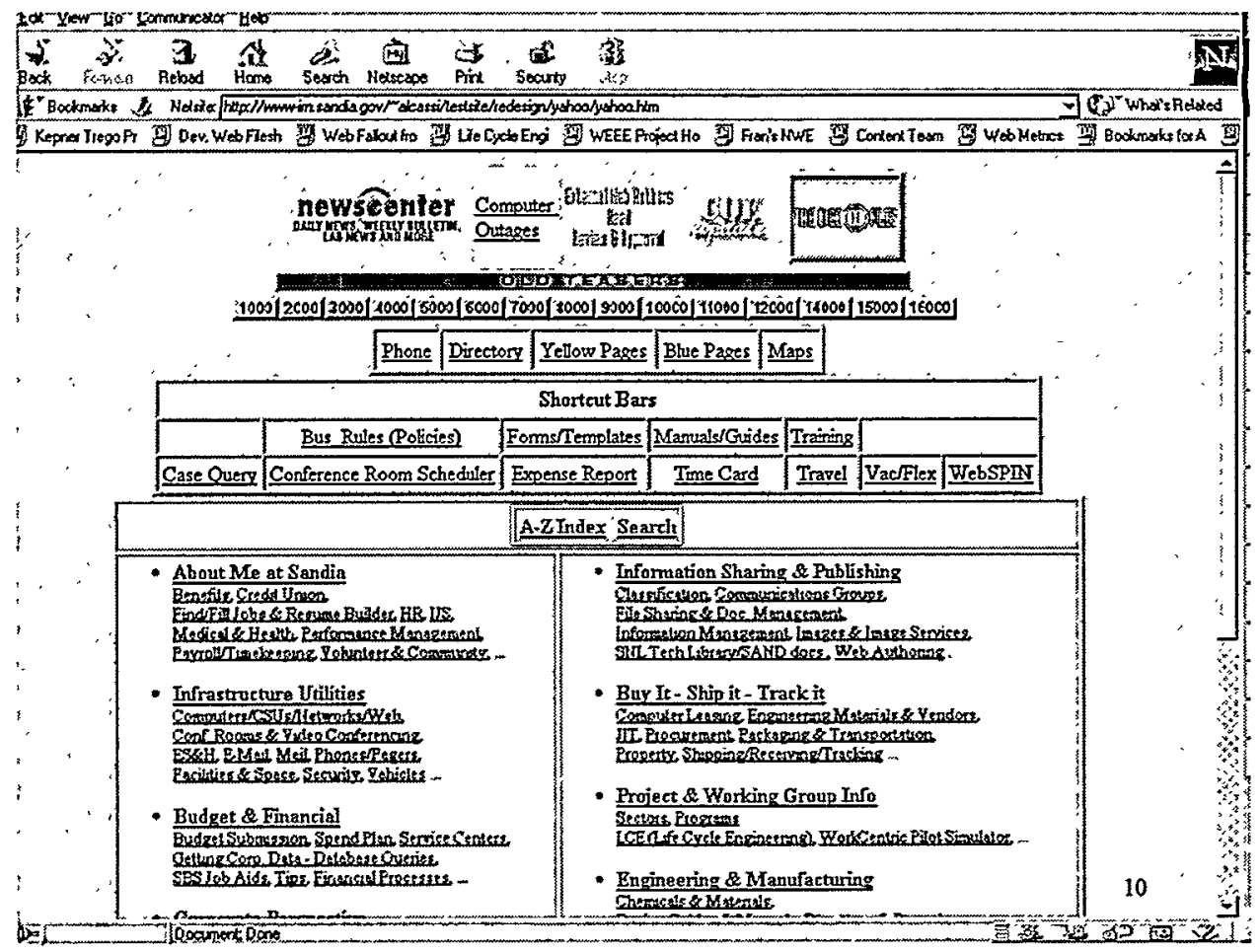

For the Phase 1 user testing a $1 \%$ randomly selected work sample (9 test subjects) of the Sandia user population was chosen. It consisted of 5 technical and 4 administrative employees from various organizations.

Phase 1 was conducted to identify any potential flaws in the usability testing protocol and provide a baseline qualitative and quantitative analysis. A mean success rate of $73 \%$ was achieved (standard deviation $20 \%$ ), the mean time on task was 113 seconds (standard deviation 52 seconds) with a mean number of paths of 1.3 .

\section{PHASE 2}

Common problems encountered among test subjects during Phase 1 were identified and solutions were implemented to remedy the problem and improve the home page design.
The basic design did not change, but we added new example links under several of the major categories on the home page. We duplicated links to certain information on multiple second level subcategories. The result was prototype 2 .

The second phase of usability testing was conducted on the improved prototype. The same major categories and the same sixteen emulations of graphic buttons were used again for the second test. The only difference between prototype 1 and prototype 2 were additional text example links on the home page, duplicate links under major categories, and duplicate links on different 2 nd level pages. 
Figure 3 - Phase 2 Prototype

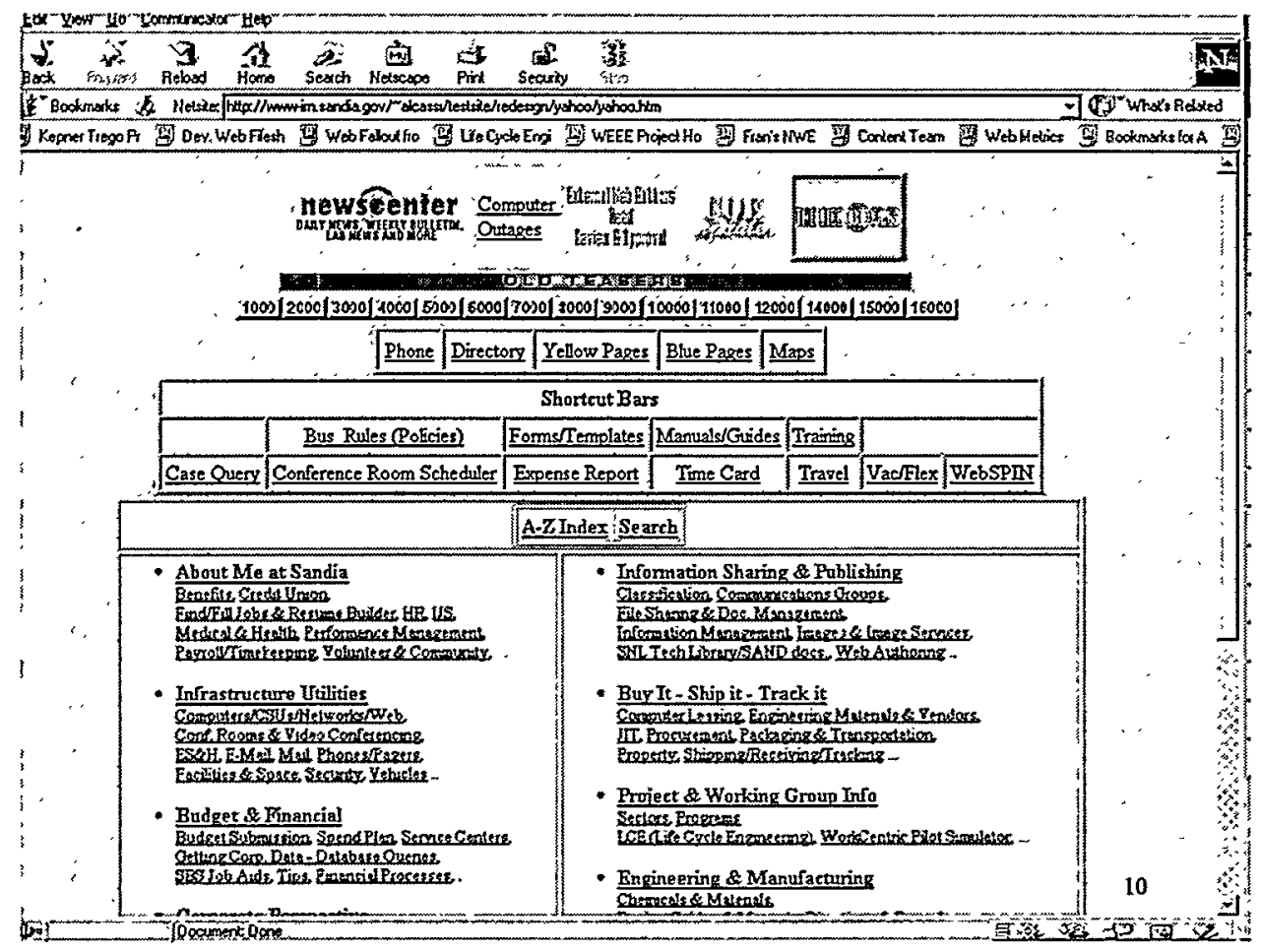

The same size subject and the same number of required tasks were used as phase 1 . A mean success rate of $84 \%$ was achieved (standard deviation 13\%), the mean time on task was 57 seconds (standard deviation 25 seconds) with a mean number of paths of 1.1 .

Common problems encountered by test subjects were noted, but solutions were not implemented. This allowed identical content between phase 2 and phase 3 usability testing.

\section{PHASE 3}

In Phase 3 a graphic artist divided the page into mock frames. He arranged buttons and graphics in the three major frames so that related items were grouped. He placed the button emulations in different positions within these frames, changed the background colors for the button emulations, and changed the color of the text on the buttons.

$\mathrm{He}$ also changed background color for the categories from blue to white, and changed the text color for the names of the major categories.
The artist introduced additional nonfunctional graphics for the search and index, which served as placeholders for the production design. The team agreed that users would not be allowed to use the new search or index graphics during phase 3 of testing. Since they had not been allowed to use the search or index button emulations during phase 1 or 2 , this allowed us to compare results of the phase 2 and phase 3 prototypes without testing new functionality.

The third phase of usability testing was conducted on prototype 3 . It produced a mean success rate of $90 \%$ ( $13 \%$ standard deviation), the mean time on task of 72 seconds (46 second standard deviation) and a mean number of paths of 1.2.

Descriptive statistics for phase 3 suggested an improvement over phase 2, but paired TTest showed no statistical (mean time on task $T$-value $=-2.33$, mean success rate $T$-value $=$ 1.19). 
Figure 4 - Phase 3 Prototype

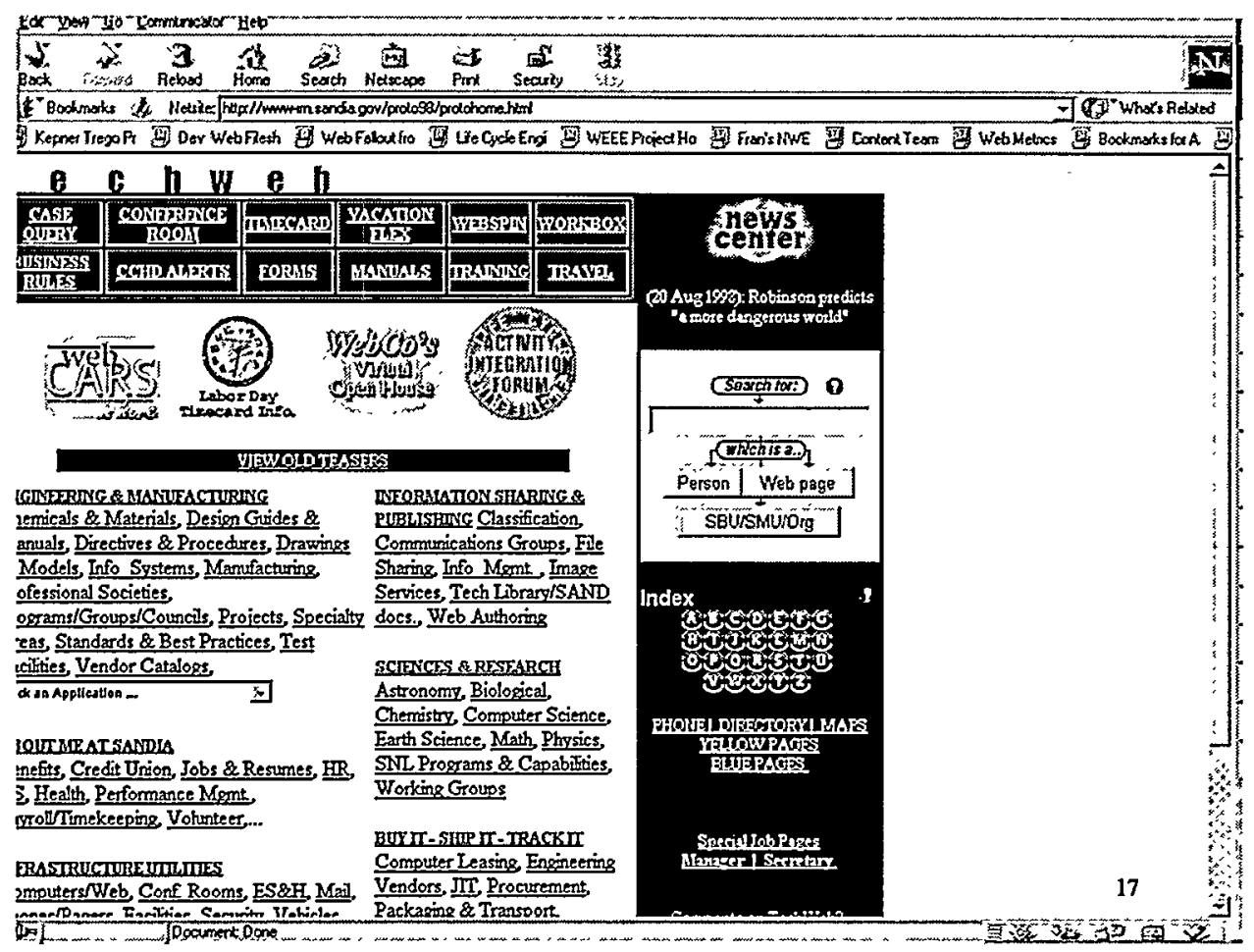

\section{DISCUSSION}

These studies quantified improvements made to the Sandia home. In this case using graphics on the home page improved success in finding desired information, but required a longer time on task. On a purely text home page the subjects were somewhat less successful locating information.

The category names seem sufficient for users to comprehend them and anticipate items associated with each label.

A pure text home page did not yield the best results with regard to success in finding desired items. Introducing graphics assisted users in locating information. A fine balance between graphics and text has to be achieved in order to make Intranets intuitive and easy to use.

When the new home page was introduced, a large number of users responded negatively to the redesign. They stated that they were not able to locate information (reasonable, since the major categories had changed for the first time since the intranet began in late 1993) and that the page was somewhat cluttered. This continued for about one month after which users became familiar with the new design and began to realize that they were able to better locate the information they needed. Users then started to respond that they could find information easier than with the old design, but the page still seemed to be too busy.

New links are continually added to the home page. Each link is examined and placed in the appropriate second level page and subcategory. It is also placed in the A-Z index under multiple keywords.

\section{ACKNOWLEDGEMENT}

Sandia National Laboratories is a multiprogram laboratory operated for the United States Department of Energy under contract DEAC04-94AL85000. 